\title{
FUNCIONALIDADE DO SULCO DO RETÍCULO EM BOVINOS ADULTOS E AVALIAÇÃO DE TÉCNICAS ALTERNATIVAS PARA PREPARAÇÃO, INFUSÃO E COLETA DE MARCADORES DA FASE FLUIDA RUMINAL
}

\author{
Reticular groove functionality in adult cattle and evaluation of alternative techniques for \\ preparation, infusion and sampling of ruminal fluid phase markers
}

\author{
João Luiz Pratti Daniel ${ }^{1}$, João Chrysostomo de Resende Júnior ${ }^{2}$, \\ Leandra Queiroz de Melo ${ }^{3}$, Rooveth Luis Melo de Souza', Mario César Guerrero ${ }^{4}$
}

\begin{abstract}
RESUMO
Os objetivos deste trabalho foram determinar a funcionalidade do sulco do retículo em bovinos adultos e avaliar técnicas alternativas para preparação, infusão e coleta de marcadores da dinâmica ruminal. Quatro vacas com cânulas ruminais foram utilizadas em três ensaios experimentais. No ensaio 1 a porcentagem de água que passou diretamente ao omaso $(27,39 \%)$ tendeu a ser menor $(P$ $=0,14)$ que a porcentagem de água que atingiu o ruminorretículo $(72,61 \%)$, indicando funcionamento ineficiente dessa estrutura em bovinos adultos. No ensaio 2, as taxas fracionais de passagem de fluido determinadas simultaneamente por Cr-EDTA $\left(14,79 \% \mathrm{~h}^{-1}\right)$ e Co-EDTA preparado por técnica alternativa $\left(14,76 \% \mathrm{~h}^{-1}\right)$ não diferiram $(P=0,96)$ e as regressões exponenciais tiveram alto coeficiente de determinação $\left(\mathrm{r}^{2}=0,90\right)$. A relação $\mathrm{Co}: \mathrm{Cr}$ no fluido ruminal não diferiu ao longo das quatro horas de coleta de amostras $(P=0,68)$. Não houve variação entre a relação $\mathrm{Co}: \mathrm{Cr}$ na urina e nas fezes. A técnica de fácil execução, proposta para preparação do Co-EDTA, mostrou-se efetiva. No ensaio 3, em que os marcadores foram infundidos à digesta sem homogeneização, a melhor plotagem $\left(\mathrm{r}^{2}=0,88 ; P<0,001\right)$ da regressão exponencial foi obtida excluindo-se os cinco primeiros tempos de coleta $(1,67 \mathrm{~h}$ após infusão) e dobrando-se os intervalos até as 5,33 h após infusão. Nesse padrão de coleta, os coeficientes de determinação das regressões exponenciais não diferiram $(P=0,17)$ de curvas padrões $\left(\mathrm{r}^{2}=1\right)$, quando comparados hipoteticamente. As técnicas alternativas propostas para infusão e amostragem são viáveis, mas requerem validação.
\end{abstract}

Termos para indexação: Co-EDTA, Cr-EDTA, Goteira Esofágica, Rúmen, Taxa de Passagem.

\section{ABSTRACT}

The objectives of this work were to determine the functionality of the reticular groove in adult cattle and to evaluate alternative techniques for preparation, infusion and collection of ruminal dynamics markers. Four cows with rumen cannulas were used in three experimental assays. In the first assay the water percentage that passed directly to the omasum $(27.39 \%)$ tended to be lower $(P=0.14)$ than the water percentage that reached the reticulorumen $(72.61 \%)$, indicating inefficient functioning of the reticular groove in adult bovines. In assay 2 , the fractional rates estimated simultaneously by Cr-EDTA (14.79\% h-1) and Co-EDTA prepared for an alternative technique (14.76\% h-1) did not differ $(P=0.96)$. The exponential regressions had a high determination coefficient $\left(\mathrm{r}^{2}=0.90\right)$. The $\mathrm{Co}: \mathrm{Cr}$ ratio in the ruminal fluid did not differ during the four hour sampling period $(P=0.68)$. There was no variation in the $\mathrm{Co}: \mathrm{Cr}$ ratio in urine or feces. The simple technique proposed for the preparation of Co-EDTA, was effective. In assay 3, markers were infused into digesta without homogenization. The best plotting $\left(\mathrm{r}^{2}=0.88 ; \mathrm{P}<0.001\right)$ of the exponential regression was obtained by excluding the five initial collection times ( $1.67 \mathrm{~h}$ after infusion) and by doubling the sampling intervals until $5.33 \mathrm{~h}$ after infusion. Under this collection pattern, the exponential regression determination coefficients did not differ $(P=0.17)$ from the standard curves $\left(\mathrm{r}^{2}=1\right)$, when hypothetically compared. The alternative techniques proposed for infusion and sampling are viable, but require validation.

Index terms: Co-EDTA, Cr-EDTA, Esophageal Groove, Rumen, Passage Rate.

(Recebido em 23 de outubro de 2006 e aprovado em 12 de fevereiro de 2007)

\section{INTRODUÇÃO}

O sulco do retículo (sulcus reticulari), zootecnicamente conhecido por goteira esofágica, apresenta-se funcional em ruminantes jovens saudáveis.
Essa estrutura atua principalmente no desvio do leite do esôfago para o abomaso ("by pass"), preservando-o da degradação ruminal. Esse reflexo é desencadeado pela sucção de líquidos e outros estímulos (ex. visual, auditivo),

\footnotetext{
${ }^{1}$ Médico Veterinário - Departamento de Medicina Veterinária/DMV - Universidade Federal de Lavras/UFLA - Cx. P. 3037 - $37200-000$ - Lavras, MG jlpdaniel@ig.com.br; rooveth10@yahoo.com.br

${ }^{2}$ Doutor, Professor - Departamento de Medicina Veterinária/DMV - Universidade Federal de Lavras/UFLA - Cx. P. 3037 - $37200-000$ - Lavras, MG joaocrj@ufla.br

${ }^{3}$ Mestre - Departamento de Zootecnia/DZO - Universidade Federal de Lavras/UFLA - Cx. P. 3037 -37200-000 - Lavras, MG - leaqmelo@yahoo.com.br ${ }^{4}$ Doutor, Professor - Departamento de Química/DQI - Universidade Federal de Lavras/UFLA - Cx. P. 3037 - $37200-000$ - Lavras, MG guerrero@ufla.br
} 
e parece ser possível a manutenção do mesmo em animais adultos (ORSKOV et al., 1970). Essa afirmação é confirmada por Woodford et al. (1984) os quais relatam que, em vacas holandesas lactantes a porcentagem de água "by pass" foi $5 \%$ e $18 \%$, respectivamente, quando as vacas foram submetidas a 9 ou 4,5 h de jejum hídrico.

O NRC (2001) cita o fornecimento de ácido DL-2OH-4-metiltiobutanóico (HMB), um precursor de metionina, para vacas em lactação sob a forma líquida como alternativa para protegê-los da degradação ruminal. Garcia et al. (2005) reportaram que o sulco do retículo mostrou-se mais efetivo em preservar ácidos graxos da biohidrogenação ruminal, do que o sabão de cálcio.

Marcadores de passagem de fluidos eficientes como Cr-EDTA (BINNERTS et al., 1968) e Co-EDTA (UDÉN et al., 1980) são os mais utilizados atualmente, bem como sua determinação por espectrofotometria de absorção atômica, já que é um procedimento rápido, confiável e de elevada sensibilidade (BINNERTS et al., 1968). Há alta correlação $(0,93)$ entre taxas de passagem de fluidos determinadas por $\mathrm{Cr}$ e Co complexados com EDTA (MAJAK et al., 1986).

Existem várias maneiras de infundir marcadores da dinâmica ruminal (ALLEN et al., 2000; DIJKSTRA et al., 1993; RESENDE JÚNIOR et al., 2006; SUTTON et al., 2003) e o modo de infusão pode interferir significativamente nos resultados. Quando se usa grande volume de soluções de marcadores (ALLEN et al., 2000) aumenta-se o volume de fluido ruminal o que pode influenciar a taxa de remoção de AGV (RESENDE JÚNIOR, 2006). Outro problema encontrado é a baixa precisão das regressões exponenciais que descrevem a queda dos marcadores ao longo do tempo refletindo homogeneização deficiente quando marcadores são adicionados sem evacuação da digesta (SUTTON et al., 2003). Por outro lado, a evacuação da digesta pode desestabilizar o ambiente ruminal e alterar a motilidade do órgão.

Os objetivos do presente trabalho foram determinar a funcionalidade do sulco do retículo em bovinos adultos, utilizando marcadores de fase fluida e avaliar técnicas alternativas para preparação, infusão e coleta de marcadores da dinâmica ruminal.

\section{MATERIAL E MÉTODOS}

Três ensaios experimentais foram realizados no Setor de Bovinocultura do Departamento de Zootecnia da Universidade Federal de Lavras entre maio de 2005 e fevereiro de 2006.

\section{Preparação da solução de Co-EDTA}

A solução de Co-EDTA foi preparada adaptando-se a metodologia proposta por Binnerts et al. (1968) para Cr-EDTA. Pesou-se 12,68 g de cloreto de cobalto (II) hexahidratado $\left(\mathrm{CoCl}_{2} \cdot 6 \mathrm{H}_{2} \mathrm{O}\right)$ num béquer de um litro e diluiu-se com $200 \mathrm{ml}$ de água destilada. Em outro béquer, dissolveu-se $20 \mathrm{~g}$ de ácido etilenodiaminotetracético dissódio $\left(\mathrm{EDTANa}_{2}\right)$ em $300 \mathrm{ml}$ de água e adicionou-se à primeira solução. A solução foi aquecida até a fervura deixando-se ebulir por uma hora. Após atingir a temperatura ambiente, complexou-se o excesso de EDTA com $4 \mathrm{ml} \mathrm{de}$ uma solução de cloreto de cálcio $10 \%$. O pH foi ajustado para seis e o volume da solução completado para um litro.

\section{Ensaio 1 - Determinação da eficácia da solução marcadora}

O primeiro ensaio objetivou determinar a eficiência da solução de Co-EDTA, preparada a partir de cloreto de cobalto. Foram utilizadas três vacas não-lactantes da raça Jersey, pesando em média $485 \mathrm{Kg}$, com cânulas implantadas no saco dorsal do rúmen. As vacas foram alimentadas com capim-elefante (Pennisetum purpureum) colhido com aproximadamente 90 dias de rebrota e com três quilos de concentrado à base de milho e soja, fornecidos como dieta total, duas vezes ao dia. Os animais permaneceram confinados num estábulo coletivo com cama de areia. Uma solução de Cr-EDTA (BINNERTS et al., 1968) foi utilizada como referência para checar os valores obtidos com o CoEDTA.

Para determinar as taxas de passagem e o volume de fluido ruminal, a digesta ruminal foi evacuada e o $\mathrm{pH}$ determinado. Adicionou-se 2,5 1 de uma solução contendo $1030 \mathrm{mg} \mathrm{l}^{-1}$ de Co-EDTA e $1030 \mathrm{mg} \mathrm{l}^{-1}$ de Cr-EDTA com pH ajustado entre 6 e 7 por meio de uma solução de $\mathrm{NaOH}$ a $50 \%$. A digesta foi homogeneizada manualmente e retornada ao ruminorretículo. Amostras de cerca de $15 \mathrm{~mL}$ de fluido ruminal foram coletadas no saco ventral, utilizando-se um tubo de PVC rígido de $3 / 4$ " com múltiplos orifícios no terço distal, acoplado à um dispositivo de sucção. As amostras foram coletadas no tempo zero (imediatamente após o retorno da digesta ao rúmen) e a cada 20 minutos até o tempo 240 minutos e foram imediatamente congeladas a $20^{\circ} \mathrm{C}$ para análises posteriores.

Amostras de sangue, fezes e urina foram coletadas no tempo zero (imediatamente antes da evacuação da digesta ruminal para infusão do marcador) e a cada oito horas até o tempo 72 horas após infusão dos marcadores.

As concentrações de $\mathrm{Co}$ e $\mathrm{Cr}$ do fluido ruminal foram determinadas no sobrenadante das amostras centrifugadas a 3000 x g por 15 minutos. As concentrações de $\mathrm{Co}$ e $\mathrm{Cr}$ no 
plasma sanguíneo foram determinadas após centrifugação (3000 g por 15 minutos) e diluição de treze vezes, devido a sua elevada viscosidade. As concentrações de Co e Cr no plasma sanguíneo foram irrelevantes. As concentrações de $\mathrm{Co}$ e $\mathrm{Cr}$ na urina foram realizadas em amostras puras ou diluídas conforme a necessidade. Para determinação das concentrações de $\mathrm{Co}$ e $\mathrm{Cr}$ nas fezes, dois gramas de fezes foram suspendidos em oito mililitros de água destilada. Essa suspensão foi centrifugada (3000 x g por 15 minutos) e o sobrenadante diluído três vezes. A quantidade de fluido nas fezes foi determinada pela subtração do conteúdo de matéria seca, determinada em estufa à $105^{\circ} \mathrm{C}$.

\section{Ensaio 2 - Quantificação da funcionalidade do sulco do retículo}

Foram utilizadas quatro vacas das raças Jersey (3) e Nelore (1), com cânulas ruminais implantadas no saco dorsal do rúmen, submetidas a jejum hídrico de $13 \pm 2$ horas, para que ingerissem água no momento em que essa fosse fornecida. Após o período de jejum, a digesta ruminorreticular foi evacuada para adição e homogeneização do marcador Cr-EDTA, e logo retornada ao órgão. A partir daí, iniciou-se um período de coleta de fluido ruminal no saco cranial, a cada 15 minutos por uma hora, para determinação do volume de fluido. Ao término deste período forneceu-se um volume de água conhecido (50 L) contendo Co-EDTA, preparado pela técnica do ensaio 1, numa concentração conhecida $\left(90 \mathrm{mg} \mathrm{L}^{-1}\right)$. A hora e o tempo de ingestão de água foram anotados. Imediatamente após a ingestão de água, iniciou-se um segundo período de coleta metodologicamente igual ao primeiro. $\mathrm{O}$ volume de água ingerido foi determinado pela mensuração do oferecido e da sobra.

As taxas fracionais de passagem de fluido ruminal, antes e após a ingestão de água, foram comparadas pelas taxas de diluição do Cr-EDTA descritas pelas regressões não lineares da queda na concentração de cromo ao longo do tempo.

\section{Ensaio 3 - Infusão de marcadores em dose única (pulse- dose) sem evacuação da digesta ruminal}

Foram utilizados os mesmos animais do ensaio 2. A vaca nelore encontrava-se em pastagem de brachiaria (Brachiaria decumbens). As vacas Jersey foram alimentadas com capim-elefante (Pennisetum purpureum) (aproximadamente 90 dias de rebrota) picado, fornecido pela manhã, e concentrado à base de milho e soja $(5 \mathrm{Kg}$ vaca $\left.{ }^{1} \mathrm{~d}^{-1}\right)$, fornecido separadamente do volumoso, duas vezes ao dia.
Antes da infusão, uma amostra de fluido ruminal de aproximadamente $100 \mathrm{~mL}$ foi coletada para determinação do pH. Três litros e meio de uma solução marcadora contendo $790 \mathrm{mg} \mathrm{L}^{-1}$ de $\mathrm{Cr}$, na forma de Cr-EDTA, foi infundida no ruminorretículo utilizando-se um funil acoplado a um tubo de PVC rígido de 3/4" com múltiplos orifícios no terço distal. Antes da infusão, a solução foi aquecida a $37^{\circ} \mathrm{C}, \mathrm{o} \mathrm{pH}$ ajustado para o $\mathrm{pH}$ ruminal inicial com solução de $\mathrm{NaOH}$ a $50 \%$ e o volume dividido em quatro partes iguais $(875 \mathrm{~mL})$, para que uma das partes fosse infundida no saco cranial e as outras infundidas em três pontos do saco ventral do rúmen. Esse escalonamento foi obtido pela estimativa do volume do saco cranial e do saco ventral, a partir da área superficial de epitélio contínuo (área epitelial menos área de papilas) determinada por Daniel et al. (2006). Pelos cálculos matemáticos estimou-se que o volume do saco ventral é três vezes maior que o volume do saco cranial, por isso, infundiu-se um quarto da solução $(875 \mathrm{~mL})$ no saco cranial e os outros três quartos $(2625 \mathrm{~mL})$ no saco ventral.

Amostras de fluido ruminal, para determinação da taxa de passagem e do volume de fluido ruminal, foram coletadas do saco ventral, no tempo zero (imediatamente após infusão do marcador) e a cada 20 minutos até o tempo 320 minutos, que foram imediatamente congeladas a $-20^{\circ} \mathrm{C}$. A cada coleta o $\mathrm{pH}$ foi determinado.

A concentração de $\mathrm{Cr}$ foi determinada no sobrenadante das amostras de fluido ruminal após centrifugação a $3000 \mathrm{~g}$ por 15 minutos.

Nesta forma de infusão espera-se que, após um período de tempo, a solução marcadora se homogeneíze à fase fluida devido a motilidade ruminal, e a partir deste momento os resultados sejam utilizados para plotagem de uma curva não linear descrevendo a queda na concentração do marcador ao longo do tempo. O momento pós-infusão ideal para iniciar a coleta de amostras foi determinado pela adequação da curva exponencial descrevendo a queda na concentração de $\mathrm{Cr}$, retirando-se gradativamente os pontos iniciais e observando-se o coeficiente de determinação $\left(\mathrm{r}^{2}\right)$.

\section{Cálculos para determinação de taxa de passagem, volume de fluido ruminal e água "by pass"}

A taxa fracional de passagem da fase fluida ruminal foi calculada pela equação exponencial descrevendo a queda na concentração ruminal do $\mathrm{Co}$ ou do $\mathrm{Cr}$ ao longo do tempo. As estimativas dessas taxas foram calculadas de acordo com a seguinte equação: 


$$
\mathrm{Q}_{\mathrm{t}}=\mathrm{Q}_{0} * \mathrm{e}^{-\mathrm{kd} * \mathrm{t}}
$$

onde:

$\mathrm{Q}_{\mathrm{t}}=$ Concentração de Co ou Cr no tempo t;

$\mathrm{Q}_{0}=$ Concentração de Co ou Cr no tempo zero;

$\mathrm{kd}=$ Taxa fracional de queda na concentração ruminal de

$\mathrm{Co}$ ou $\mathrm{Cr} \mathrm{e}$

$\mathrm{t}=$ tempo.

$\mathrm{O}$ volume de fluido ruminal foi calculado pela concentração do elemento ( $\mathrm{Co}$ ou $\mathrm{Cr}$ ) no tempo zero, que foi estimada pelo intercepto da regressão não-linear descrevendo a queda na concentração ruminal ao longo do tempo, através da equação:

$$
\mathrm{Vm} * \mathrm{Cm}=(\mathrm{Vfr}+\mathrm{Vm}) * \mathrm{Ct}_{0}
$$

onde:

$\mathrm{Vm}=$ Volume de solução marcadora infundida;

$\mathrm{Cm}$ = Concentração de Co ou Cr na solução marcadora;

$\mathrm{Vfr}=$ Volume de fluido ruminal e

$\mathrm{Ct}_{0}=$ Concentração de marcador no fluido ruminal no tempo zero.

A porcentagem de água "by pass" foi determinada pela seguinte equação: $\operatorname{ABP}(\%)=[(\mathrm{AI}-\mathrm{ARR}) / \mathrm{AI}]^{*} 100$, onde: $\mathrm{ABP}=$ Água "by pass"; $\mathrm{AI}=$ Volume de água ingerida $(\mathrm{L}) \mathrm{e}$ $\mathrm{ARR}=$ Volume de água ingerida que atingiu o ruminorretículo.

\section{Análises estatísticas}

As concentrações de $\mathrm{Co}$ e $\mathrm{Cr}$, a relação $\mathrm{Co}: \mathrm{Cr}$ medida ao longo do tempo no fluido ruminal, na urina e nas fezes (ensaio 1), foi analisada como medidas repetidas, pelo procedimento MIXED do pacote estatístico SAS (LITTEL et al., 1996) de acordo com o seguinte modelo:

$$
Y_{i j k}=\mu+V_{i}+M_{j}+P_{k}+M_{j} * P_{k}+e_{i j k}
$$

onde:

$\mu=$ Média geral;

$\mathrm{V}_{\mathrm{i}}=$ Efeito de vaca $(\mathrm{i}=1$ a 3$)$;

$\mathrm{M}_{\mathrm{j}}=$ Efeito do material coletado $(\mathrm{j}=$ fluido ruminal, urina ou fezes);

$\mathrm{P}_{\mathrm{k}}=$ Efeito do tempo de coleta e $\mathrm{e}_{\mathrm{ijk}}=$ Erro.

A porcentagem de água "by pass" (ensaio 2), foi analisada pelo procedimento GLM do pacote estatístico SAS de acordo com o seguinte modelo:

onde:

$$
\mathrm{Y}_{\mathrm{ij}}=\mu+\mathrm{V}_{\mathrm{i}}+\mathrm{C}_{\mathrm{j}}+\mathrm{e}_{\mathrm{ij}}
$$

$\mu=$ Média geral;
$\mathrm{V}_{\mathrm{i}}=$ Efeito de vaca $(\mathrm{i}=1 \mathrm{a} 4)$;

$\mathrm{C}_{\mathrm{j}}=$ Efeito de compartimento $(\mathrm{j}=$ ruminorretículo ou omaso)

$\mathrm{e}_{\mathrm{ij}}^{\mathrm{j}}=$ Erro, independente e identicamente distribuído com média zero e variância $\sigma^{2}$.

O mesmo procedimento foi utilizado para a análise da taxa de passagem de fluido ruminal e do volume de fluido ruminal, nos ensaios 1, 2 e 3 e dos coeficientes de determinação das regressões não lineares representando a queda na concentração dos marcadores ao longo do tempo, nos ensaios 1 e 3, substituindo-se o efeito de compartimento pelo efeito do tipo de marcador ( $\mathrm{j}=\mathrm{Co}$-EDTA ou Cr-EDTA).

\section{RESULTADOS E DISCUSSÃO}

\section{Eficácia da solução de Co-EDTA adaptada}

As taxas fracionais de passagem determinadas simultaneamente pelo Cr-EDTA e pelo Co-EDTA não diferiram, assim como os coeficientes de determinação das regressões $\left(\mathrm{r}^{2}\right)$ não lineares representando a queda na concentração dos marcadores ao longo do tempo (TABELA 1). O volume de fluido ruminal estimado pelo $\mathrm{Cr}$ EDTA tendeu a ser maior do que o volume estimado pelo Co-EDTA (TABELA 1). Majak et al. (1986) estudando a relação entre a taxa fracional de passagem de fluido ruminal e a ocorrência de timpanismo em vacas alimentadas com alfafa imatura fresca, utilizaram Co-EDTA (UDÉN et al., 1980) e Cr-EDTA (BINNERTS et al., 1968) como marcadores de fase fluida. Neste estudo, os autores observaram uma alta correlação $(0,93)$ entre as taxas de passagem determinadas por Cr-EDTA e Co-EDTA. No mesmo experimento, o volume de fluido ruminal determinado pelo intercepto da equação exponencial, que representa a queda na concentração do marcador no fluido ruminal, foi diferente entre animais quando determinado pelo CoEDTA, mas não diferiu quando estimado pelo Cr-EDTA. Os autores sugeriram que o Co-EDTA é disperso mais rapidamente que o Cr-EDTA. Houve tendência do CoEDTA estimar um maior volume de fluido ruminal do que o Cr-EDTA. Entretanto, apesar dos dados serem conflitantes com os do presente experimento, as diferentes metodologias de adição de marcadores dificultam a comparação direta dos resultados.

A relação $\mathrm{Co}: \mathrm{Cr}$ no fluido ruminal (média =1,47; $\mathrm{EPM}=0,02)$ não foi diferente ao longo das quatro horas de coleta de amostras $(P=0,68)$. Da mesma forma, não houve variação entre a relação Co : Cr na urina e nas fezes $(P=$ 0,34 para efeito do material coletado; $P=0,47$ para efeito do tempo; $P=0,58$ para interação entre tempo e material coletado), demonstrando a similaridade entre os marcadores utilizados. 
Tabela 1 - Taxas fracionais de passagem, coeficientes de determinação das regressões e volumes de fluido ruminal estimados pelos marcadores Cr-EDTA e Co-EDTA, infundidos simultaneamente em vacas não lactantes consumindo capim elefante e concentrado.

\begin{tabular}{cccc}
\hline & $\begin{array}{c}\text { Taxa fracional de } \\
\text { passagem }(\mathrm{kp})\end{array}$ & $\begin{array}{c}\text { Coeficiente de determinação da } \\
\text { regressão }\left(\mathrm{r}^{2}\right)\end{array}$ & $\begin{array}{c}\text { Volume de fluido ruminal } \\
\text { estimado }\end{array}$ \\
\hline Cr-EDTA & $14,79 \% \mathrm{~h}^{-1}$ & 0,90 & $44,06 \mathrm{~L}$ \\
Co-EDTA & $14,76 \% \mathrm{~h}^{-1}$ & 0,90 & $41,76 \mathrm{~L}$ \\
EPM $^{1}$ & 0,39 & 0,01 & 0,49 \\
$P^{2}$ & 0,96 & 0,93 & 0,08 \\
\hline
\end{tabular}

${ }^{1}$ EPM: Erro Padrão da Média.

${ }^{2} P$ : Nível de significância.

O pico dos marcadores na urina e nas fezes ocorreu por volta de oito e 16 horas $(\mathrm{EPM}=8,60)$ respectivamente após a infusão ruminal $(P<0,001$ para interação entre tempo e material coletado).

Trabalhos pesquisando concentração urinária de marcadores após infusão ruminal não foram encontrados na literatura. Udén et al. (1982) estudando o tempo de retenção da fase fluida da digesta em diversas espécies, puderam detectar o aparecimento do marcador nas fezes dez horas após a infusão ruminal em novilhas consumindo feno. Estes autores observaram um tempo de retenção de fluido em novilhas maior que em carneiros e cabras. Comparando-se os dados do presente trabalho com os obtidos em ovelhas por Vega et al. (1998), que encontraram um pico de Co-EDTA nas fezes 6,5 horas após infusão ruminal do marcador, verifica-se o mesmo comportamento descrito por Udén et al. (1982).

\section{Funcionalidade do sulco do retículo}

A ingestão de água $(32 \pm 15 \mathrm{~L})$ ocorreu de forma intermitente por dez minutos. A porcentagem de água "by pass" $(27,39 \%)$ tendeu a ser menor $(P=0,14)$ do que a porcentagem de água que atingiu o ruminorretículo $(72,61$ \%) $(\mathrm{EPM}=16,22)$. Woodford et al. (1984) observaram um consumo de 38 litros de água com polietilenoglicol (PEG), em vacas submetidas a jejum hídrico de nove horas. Apesar da ingestão de água ter sido semelhante, a porcentagem de água "by pass" foi menor (5\%). A diferença provavelmente deve-se à metodologia utilizada por Woodford et al. (1984), pois parte do PEG pode se incorporar à fase sólida, resultando numa superestimativa da diluição do marcador (TEETER \& OWENS, 1983). Além disso, há uma superestimativa do volume de fluido ruminal quando determinado por meio da matéria seca da digesta (RESENDE JÚNIOR et al., 2006).

A taxa fracional de passagem de fluido antes da ingestão de água $\left(18,75 \% \mathrm{~h}^{-1}\right)$ foi maior $(P<0,001)$ do que após a ingestão $\left(2,86 \% \mathrm{~h}^{-1}\right)(\mathrm{EPM}=0,68)$. Provavelmente isso ocorreu porque a taxa de passagem de fluido, em litros por hora, não foi alterada na mesma proporção do volume de fluido ruminal. Trabalhos que compararam a taxa fracional de passagem de fluido, antes e após a ingestão de água, não foram encontrados na literatura. Entretanto, o volume de fluido ruminal foi negativamente correlacionado com a taxa de passagem de fluido em vacas holandesas alimentadas com azevém fresco e concentrado (RESENDE JÚNIOR et al., 2006).

A partir desses resultados nota-se que a maior parte da água ingerida (72\%) atinge o ruminorretículo. A ingestão de água com baixas temperaturas pode comprometer a atividade enzimática ruminal, já que as enzimas requerem uma temperatura ótima para sua máxima atividade (LEHNINGER et al., 1995). Brod et al. (1982) observaram uma menor produção de amônia e AGV em carneiros que ingeriram água a $0^{\circ} \mathrm{C}$ quando comparados com vacas que ingeriram água a 10,20 ou $30^{\circ} \mathrm{C}$. Em seu experimento, Wilks et al. (1990) perceberam que $98 \%$ das vacas leiteiras preferiram água morna ao invés de água fria, provavelmente um reflexo fisiológico que evitaria a diminuição do aporte energético.

\section{Infusão de marcadores em pulse-dose sem evacuação da digesta ruminal}

A melhor plotagem $\left(\mathrm{r}^{2}=0,88 ; P<0,001\right)$ foi obtida excluindo-se os cinco primeiros tempos de coleta $(1,67 \mathrm{~h}$ após a infusão) e dobrando-se os intervalos até as 5,33 h 
após a infusão. Os coeficientes de determinação das regressões não lineares representando a queda da concentração dos marcadores ao longo do tempo, obtidos da forma descrita, não diferiram $(P=0,17)$ de curvas padrões $\left(r^{2}=1\right)$, quando comparados hipoteticamente. Uma melhor adequação das regressões não lineares que descrevem a queda na concentração de marcadores ao longo do tempo pode ser obtida utilizando-se a primeira coleta $1,5 \mathrm{~h}$ após infusão do marcador, a segunda coleta 15 minutos após a primeira, a terceira 30 minutos após a segunda e assim sucessivamente dobrando-se os intervalos de coleta (FIGURA 1).

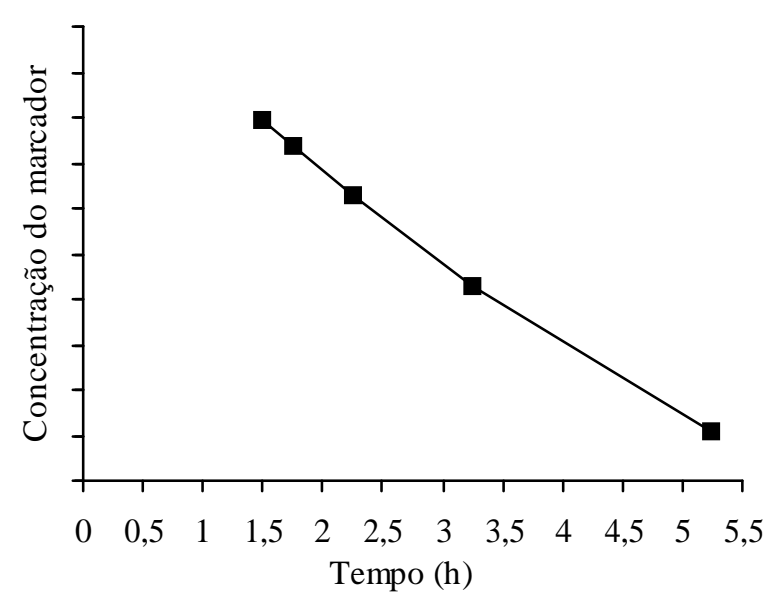

Figura 1 - Proposta de tempos de coleta de líquido ruminal para determinação de marcadores da cinética da fase fluida.

\section{CONCLUSÕES}

O sulco do retículo em bovinos adultos apresenta funcionamento deficiente limitando a eficácia das práticas nutricionais que contam com o seu pleno funcionamento. A modificação da técnica de preparação do Co-EDTA mostrou-se efetiva e as técnicas alternativas propostas para infusão e amostragem de marcadores são viáveis, mas requerem validação.

\section{REFERÊNCIAS BIBLIOGRÁFICAS}

ALLEN, M. S.; ARMENTANO, L. E.; PEREIRA, M. N.; YING, Y.; XU, J. Method to measure fractional rate of volatile fatty acid absorption from the rumen. In:
CONFERENCE ON RUMEN FUNCTION, 25., 2000, Chicago. Proceedings... Chicago: [s.n.], 2000. p. 2425.

BINNERTS, W. T.; VAN'T KLOOSTER, A. T.; FRENS, A. M. Soluble chromium indicator measured by atomic absorption in digestion experiments. The Veterinary Record, London, v. 82, p. 470, 1968.

BROD, D. L.; BOLSEN, K. K.; BRENT, B. E. Effect of water temperature on rumen temperature, digestion and rumen fermentation in sheep. Journal of Animal Science, Savoy, v. 54, n. 1, p. 179-182, 1982.

DANIEL, J. L.; RESENDE JÚNIOR, J. C.; CRUZ, F. J. Participação do ruminoretículo e omaso na superfície absortiva total do proventrículo de bovinos. Brazilian Journal of Veterinary Research and Animal Science, São Paulo, v. 43, n. 5, p. 688-694, 2006.

DIJKSTRA, J.; BOER, H.; BRUCHEM, J. van; BRUINING, M.; TAMMINGA, S. Absorption of volatile fatty acids from the rumen of lactating dairy cows as influenced by volatile fatty acid concentration, $\mathrm{pH}$ and rumen liquid volume. British Journal of Nutrition, Wallingford, v. 69, n. 2, p. 385-396, 1993.

GARCIA, C. D.; HERNANDEZ, M. P.; CANTALAPIEDRA, G.; SALAS, J. M.; MERINO, J. A. Bypassing the rumen in dairy ewes: the reticular groove reflex vs. calcium soap of olive fatty acids. Journal of Dairy Science, Savoy, v. 88, n. 2, p. 741-747, 2005.

LEHNINGER, L. A.; NELSON, D. L.; COX, M. M.Princípios de bioquímica. Tradução por Arnaldo Antônio Simões e Wilson Roberto Navega Lodi. 2. ed. São Paulo: Sarvier, $1995.839 \mathrm{p}$.

LITTEL, R. C.; MILLIKEN, G. A.; STROUP, W. W.; WOLFINGER, R. D.SAS $®$ system for mixed models. Cary, 1996. $633 \mathrm{p}$.

MAJAK, W.; HALL, J. W.; RODE, L. M.; KALNIN, C. N. Rumen clearance rates in relationship to the occurrence of alfafa bloat in cattle: 1. passage of water-soluble markers. Journal of Dairy Science, Savoy, v. 69, p. 15601567, 1986. 
NATIONAL RESEARCH COUNCIL. Nutrient requirements of dairy cattle. 7 . ed. Washington: National Academy of Science, 2001. 408 p.

ORSKOV, E. R.; BENZIE, D.; KAY, R. N. B. The effects of feeding procedure on closure of the esophageal groove in young sheep. British Journal of Nutrition, Wallingford, v. 24, p. 785-795, 1970.

RESENDE JÚNIOR, J. C.; PEREIRA, M. N.; BOHER, H.; TAMMINGA, S. Comparison of techniques to determine the clearance of ruminal volatile fatty acids. Journal of Dairy Science, Savoy, v. 89, n. 7, p. 30963106, 2006.

SUTTON, J. D.; DHANOA, M. S.; MORANT, S. V.; FRANCE, J.; NAPPER, D. J.; SCHULLER, E. Rates of production of acetate, propionate, and butyrate in the rumen of lactating dairy cows given normal and low-roughage diets. Journal of Dairy Science, Savoy, v. 86, p. 3620-3633, 2003.

TEETER, R. G.; OWENS, F. N. Characteristics of water soluble markers for measuring rumen liquid volume and dilution rate. Journal of Animal Science, Savoy, v. 56, p. 717-728, 1983.
UDÉN, P.; COLUCCI, E.; SOEST, P. J. van. Investigation of chromium, cerium and cobalt as markers in digesta rate of passage studies. Journal of the Science of Food and Agriculture, London, v. 31, p. 625-632, 1980.

UDÉN, P.; ROUNSAVILLE, T. R.; WIGGANS, G. R.; SOEST, P. J. van. The measurement of liquid and solid digesta retention in ruminants, equines and rabbits given timothy (Phleum pratense) hay. British Journal of Nutrition, Wallingford, v. 48, p. 329-339, 1982.

VEGA, A.; GASA, J.; CASTRILLO, C.; GUADA, J. A. Passage through the rumen and the large intestine of sheep estimated from fecal marker excretion curves and slaughter trials. British Journal of Nutrition, Wallingford, v. 80, p. 381-389, 1998.

WILKS, D. L.; COPPOCK, C. E.; LANHAM, J. K.; BROOKS, K. N.; BAKER, C. C.; BRYSON, W. L.; ELMORE, R. G.; STERMER, R. A. Responses of lactating holstein cows to chilled drinking water in high ambient temperatures. Journal Dairy Science, Savoy, v. 73, p. 1091-1099, 1990.

WOODFORD, S. T.; MURPHY, M. R.; DAVIS, C. L.; HOLMES, K. R. Ruminal bypass of drinking water in lactanting cows. Journal of dairy Science, Savoy, v. 67, p. 2471-2474, 1984. 